DOi: 10.21554/hrr.042004

\title{
LONELINESS OF HIGH SCHOOL AND COLLEGE STUDENTS: THE RELATION OF SOCIO-DEMOGRAPHIC CHARACTERISTICS AND SELF-ESTEEM WITH LONELINESS
}

Original scientific paper

\section{Nataša Kostić1 \\ Šuajb Solaković}

${ }^{1}$ Psychology Department, Faculty of Philosophy, University of East Sarajevo, Bosnia and Herzegovina

Received: $12 / 18 / 2019$

Accepted: $3 / 5 / 2020$

\begin{abstract}
The research problem relates to the examination of the relationof socio-demographic characteristics (gender, level of education and the place where most of childhood was spent) and the self-esteem of the respondents with loneliness.In investigating this problem, the focus was primarily on the perception of the distribution of loneliness, and the examination of the relation of independent variables (socio-demographic characteristics and self-esteem) with the dependent variable (loneliness).The sample of respondents consists of 677 high school students (49.34\%) and college students (50.66\%) of Bosnia and Herzegovina. The range of years of subjects ranges from 15 to 23 (AS=18.696). The results of the study show that there is a statistically significant difference in loneliness with regard to gender $(U=38672.000, Z=-6.122$, $p=.000)$, to the level of education $(U=42292.500, Z=-5.905, p=.000)$ and the place in which the respondents spent most of their childhood $\left(\chi^{2}=9.383, d f=2\right.$, sig $\left.=.009\right)$. The results show that there is a statistically significant relation between self-esteem and loneliness $\left(r_{o}=-.401\right.$, sig $\left.=.000, N=676\right)$.
\end{abstract}

Keywords: Loneliness, self-esteem, socio-demographic characteristics, high school, students

\footnotetext{
${ }^{1}$ Correspondence to:

Nataša Kostić Psychology Department, Faculty of Philosophy, University of East Sarajevo, Bosnia and Herzegovina Pale, Republic of Srpska, Bosnia and Herzegovina

E-mail: natasa.kostic@ffuis.edu.ba,
} 


\section{INTRODUCTION}

The human is a social being and, as such, strives to enter into different social contacts, associates with others and creates close and intimate relationships with them. The social contacts it strives are both quantitative and qualitative in nature.The feeling that he lacks quantity or quality, or both aspects of social relations is perceived by the individual as loneliness. An individual can have a large number of social relationships and feel alone, but also lead a rather lonely life, but not feel lonely.De Jong Gierveld, Van Tilburg, Dykstra (2006) state that the conceptualization of loneliness began in the late 1950s, and that empirical research was spurred by the work of Perlman and Pepla (1981), which defined it as an unpleasant experience that happens when a network of social relationships of an individual is defective in some important way, whether quantitative or qualitative. The standard for optimal quantity and quality of social relationships does not exist. It is subjectively determined and represents the desired relationships of the individual. Precisely because of the subjective feeling of a lack of satisfactory social relationships, the individual begins to experience loneliness. Hombrados-Mendieta, García-Martín, Gómez-Jacinto (2012) consider that it reflects the interpersonal deficit that arises as a result of fewer or less satisfactory relationships than an individual wants. Asher and Paquette (2003, according to Akin, 2010) define loneliness as a cognitive awareness of the lack of social and personal relationships, accompanied by affective reactions of sorrow, emptiness and longing. The definition points two aspects of loneliness, which are both cognition and emotion. It is obvious that loneliness results from a cognitive assessment of individual relationships, which are followed by emotions in relation to those assessments. By defining loneliness as a situation experienced by an individual in relation to an unpleasant or unacceptable deficiency (quality) of certain relationships, De Jong Gierveld (1998) points out that it includes three components: 1) feelings about abscence of intimate attachment, feeling of emptiness or abandonment, 2 ) a time perspective (people interpret their loneliness situation as hopeless or as changeable and curable, blame others or themselves for the situation in which they are), 3) the comprehension of different types of emotional aspects, such as sadness, regret, shame, guilt, frustration and desperate. Approaches to loneliness are different, so it is possible to distinguish several types and sorts of loneliness. There are differences in the perception of loneliness as a one-dimensional or multidimensional construct. According to the multidimensional understanding there are different types of loneliness. Weiss (1987, according to Hombrados-Mendieta, García-Martín, GómezJacinto, 2012) distinguishes two types of loneliness, which are: emotional and social.Emotional loneliness is perceived as a lack of attachment in relations and is associated with a feeling of emptiness and the desire to share life with a particular one. Social loneliness arises from the lack of a social network (friends, colleagues, neighbors) and leads to feelings of being rejected by others. This division suggests that the first type refers to the lack of quality, and the second is the lack of the quantity of social relations.Garson and Perlman (1979, according to Javeed, 2011) distinguish chronic and temporal loneliness. Both types present a subjective state of emotional discomfort due to the lack of social and emotional relationships, with the first being a more permanent state, while the second occurs occasionally as a result of life-changing or situations that hinder the social life of an individual in a shorter period of time. Loneliness is common both for children and adults. Some data show that $80 \%$ under the age of $18,40 \%$ over 65 , declare that at times they feel lonely (Weeks, 1994; Pinquart, Sorensen, 2001; Berguno, Leroux, McAinsh, Shaikh, 2004, according to Hawkley, Cacioppo, 2010 ).Mahon, Yarcheski, Yarcheski, Cannella, Hanks (2006, according to Lasgaard, Elklit, 2009) point out that the results of the study show that loneliness increases during adolescence, while Heinrich, Gullone (2006, according to Lasgaard, Elklit, 2009) state that during this period it is most widespread. 
The loneliness of adolescents can be normative due to significant changes in social expectations and needs, and thus represents a natural part of life and is to some extent considered positive, ie, the source of personal development (Lesgaard, Elklit, 2009). Adolescents face various events such as changes, school obligations and obligations during studies, future planning, economic difficulties, family relationships (Woodward, Kalyan-Masih, 1990; Byrne, Devenport, Mazanov, 2007; Moon, Rao, 2010; Thorsteinsson, Ryan, Sveinbjornsdottir, 2013) that contribute to loneliness. During this period, they search for their own identity, and contacts and closeness with peers are important for their proper functioning.Coping with all of these can contribute to the feeling of a lack of quantity and quality of social relationships, that is, to experiencing loneliness. Nekić, Uzelac, Jurkin (2016) state that on the basis of the research it is possible to distinguish five factors that contribute to the appearance of loneliness in adolescence, which are: 1) physical changes, 2) cognitive changes, 3 ) changes in social relations, 4) establishment of autonomy and individuation; and 5) the development of identity. Berk (2008) considers that in the period of adolescence the development of abstract thinking enables the imagination of possible and ideal as well as perfect social relationships, which contributes to increased sensitivity to the quantity and quality of current relationships. When it comes to differences in loneliness with regard to the gender, they did not give unambiguous results, but some authors (Lacković-Grgin, Penezić, Sorić, 1998) suggest that more research suggests that men are more lonely than women.Researchers from different authors have shown that men are more lonely than women (Lacković-Grgin, Penezić, Sorić, 1998; Koc, 2012). On the other hand, some studies have found that women are more lonely than men (Victor, Yang, 2012; Javeed, 2011; Baran, Baran, Maskan, 2015;), while Neto (2014), as well as Nekić, Uzelac, Jurkin (2017 ) did not find differences in loneliness with respect to the gender of the respondents.Stickley et al. (2016) in their researches carried out on a sample of respondents from a year span of 13 to 15 years in the United States, Russia and the Czech Republic have found that loneliness is to a greater extent characterized by adolescent women than adolescent men.For a higher level of loneliness in men than women, authors point out that they are less likely to expect social relationships and are less fortunate in them (Claes, 1992, according to Medved, Keresteš, 2011), and because of that, they feel lonely, while others, as a reason, state their poor ability to express feelings (Wiesman, Guttfreund, 1995, according to Medved, Keresteš, 2011). Authors explain higher levels of loneliness of the female gender than male as that because they value interpersonal relationships more (Al Khatib, 2012; Anderson et al., 1983; Yaacob et al., 2009, according to Nekić, Uzelac, Jurkin, 2017). The results of the research are also not unambiguous when it comes to differences in the loneliness of younger and older adolescents. Baran, Baran, Maskan (2015) did not find differences in loneliness among adolescents of different grades, as well as of age, in their research.On the other hand, some studies have shown that younger adolescents are lonelier than older adolescents (Mahon, 1983; Mijušković, 1986; Nekić, Uzelac, Jurkin, 2016), while others have shown that older adolescents are lonelier than younger ones (Brage, Meredith, 1993 Chipuer, Pretty, 2000). When it comes to the relation between the quantity of social relations and loneliness, it can be concluded that the quality of social relations rather than quantity significantly influences loneliness. On the basis of the results of several studies, Jackson, Soderlind, Weiss (2000) cite several aspects of social relationships that are important determinants of loneliness: satisfaction with their own social networks, the experience of closeness and intimacy in interpersonal relationships, the knowledge that they can count on the support of people from their own social networks and their involvement in a social network whose members are highly interconnected. In addition to the sociodemographic characteristics in the study of loneliness, its relationship with self-esteem was seen. 
Mead (1934, according to Milošević, Ševkušić, 2005), as one of the first authors who give a definition of self-esteem, considers that it is the way in which an individual values himself and that it is the result of an individual's interaction with significant others. Coopersmith (1967, according to Heatherton, Vox (2000) defines self-esteem as an individual's evaluation of himself that expresses the attitude of approval, ie to what extent does he/she believe that he/she is capable, significant, valuable, and successful. Rosenberg (1968, 1979; Simons, 1987) views self-esteem as a general negative or positive attitude towards oneself. Vanhalst, Luyckx, Scholte, Engels, Goosens (2013) state that low self-esteem follows the current, but also later, feeling of loneliness in adolescence. These longitudinal studies have determined that there is a significant connection between self-esteem and loneliness. Baran, Baran, Maskan (2015), as well as Nekić, Uzelac, Jurkin (2016) have established a negative correlation between self-esteem and loneliness. Earlier researches (Rubin, Mills, 1991, Cash, 1995) pointed low self-esteem as a significant factor of loneliness. Stickley et al. (2016) point out that adolescents often feel lonely and that low selfesteem is associated with it. Tucak Junaković, Nekić, Burić (2013) point out that a number of studies show that loneliness leads to psychosomatic problems and mental health disorders. Given that the development of self-esteem is determined by environmental factors and that its development can be influenced. Examination of the relationship between self-esteem and loneliness would allow us to look at those factors that would potentially contribute to the negative effects of loneliness. In an exploratory sense, it would be necessary to take into account the socio-demographic characteristics of the respondents when considering self-esteem. It is possible that such research would allow us to examine the impact of certain variables on loneliness.

\section{PROBLEM AND TASKS OF RESEARCH}

Given that loneliness can lead to certain disorders (Tucak Junaković, Nekić, Burić 2013) and therefore adequate functioning of individuals, we can say that research on loneliness is a social problem that should be taken more seriously. The research problem relates to the examination of the relation of socio-demographic characteristics (gender, level of education and the place where most of childhood was spent) and the self-esteem of the respondents with loneliness. In investigating this problem, the focus was primarily on the perception of the distribution of loneliness, and the examination of the relation between self-esteem and loneliness, and the difference in manifestation of loneliness with respect to the sociodemographic characteristics of the respondents. of independent variables, sociodemographic characteristics and self-esteem) with the dependent variable (loneliness). In accordance with the above, the following research tasks were set up:

1) examine and analyze the distribution of loneliness,

2) examine and analyze the differences of the respondents in loneliness with regard to their sociodemographic characteristics (gender, level of education and the place where most of childhood was spent),

3) examine and analyze the relationship of selfesteem and loneliness of the respondents.

\section{METHODS}

Data collection was performed in the 2017-2018 academic year, respectively. The sample consists of 677 students of high school and college students of Bosnia and Herzegovina (58.94\% of respondents from Republika Srpska and $41.06 \%$ from Federation of Bosnia and Herzegovina). The sample is consistent with whether the respondents attend high school or are college students. In this study we use convenience sampling, Data were collected in schools and colleges where research was possible. The age of subjects ranges from 15 to 23 (AS = 18.696). Self-assessment of respondents was used to determine where most of childhood was spent. The sample structure is shown in Table 1. 


\begin{tabular}{|c|c|c|c|}
\hline \multicolumn{2}{|l|}{ Specimen of the sample } & \multirow{2}{*}{$\begin{array}{c}\text { Frequency } \\
423\end{array}$} & \multirow{2}{*}{$\begin{array}{c}\text { Percentage } \\
62.48\end{array}$} \\
\hline \multirow{2}{*}{ Gender } & Female & & \\
\hline & Male & 254 & 37.52 \\
\hline Level of education & $\begin{array}{l}\text { High school } \\
\text { student } \\
\text { College student }\end{array}$ & $\begin{array}{l}334 \\
343\end{array}$ & $\begin{array}{l}49.34 \\
50.66\end{array}$ \\
\hline Grade & $\begin{array}{l}\text { First } \\
\text { Second } \\
\text { Third } \\
\text { Fourth } \\
\end{array}$ & $\begin{array}{c}50 \\
107 \\
111 \\
66 \\
\end{array}$ & $\begin{array}{l}14.97 \\
32.04 \\
33.23 \\
19.76 \\
\end{array}$ \\
\hline \multirow{4}{*}{ Year of study } & First & 113 & 32.94 \\
\hline & Second & 120 & 34.99 \\
\hline & Third & 54 & 15.74 \\
\hline & Fourth & 56 & 16.33 \\
\hline The place where most of childhood was spent & $\begin{array}{l}\text { Countryside } \\
\text { Minor settlement } \\
\text { City }\end{array}$ & $\begin{array}{l}209 \\
172 \\
285\end{array}$ & $\begin{array}{l}31.38 \\
25.83 \\
42.79\end{array}$ \\
\hline
\end{tabular}

\section{Research instruments}

The research used the following instruments:

Questionnaire for collecting data on the socio-demographic characteristics of the respondents (age, gender, level of education, the place where the most of childhood was spent), The Rosenberg self-esteem scale was used to examine self-esteem (RSS) (Rosenberg, 1965). The scale contains 10 statements, of which 5 are positively worded and 5 are negatively worded. In order to calculate the total score of the respondents on the scale for negative claims, the inverted values of the answer are so that the higher score achieved indicates a higher level of self-esteem. An example of a positively worded statement is, "I think I'm worth at least as much as other people," and the negative is, "I feel I don't have much to be proud of." The values of the answers to the question, "How much do the following statements apply to you?" That respondents could choose for each statement on the scale are the following: 1 - does not apply to me at all, 2 - generally does not apply to me. 3 - neither relates to nor applies to me, 4 - mainly applies to me, 5 - fully applies to me. Higher scores on the scale indicate more self-esteem.

An adapted version of the short UCLA Loneliness Scale, constructed by Allen and Oshagan, was used to test loneliness (1995, prema Lacković-Grgin, Penezić, Nekić, 2002). The adaptation of the Croatian-speaking scale was performed by Lacković-Grgin, Penezić, Nekić (2002). The scale contains seven statements, some of which are: "I have not been close to anyone for a long time" and "People are around me, but not with me." Respondents were able to answer the statements as follows regarding their own experience of self: 1 - does not apply to me at all, 2 - does not apply to me mainly, 3 - neither relates nor relates to me , 4 - mostly applies to me, 5 - totally applies to me. 
All claims are formulated so that achieving a higher score indicates a higher expression of loneliness, which means that a higher score on the scale indicates a higher loneliness expression. The instruments were adapted to the respondent's speech area.

\section{RESULTS OF RESEARCH}

An analysis of the results related to the distribution of loneliness found that it statistically deviates significantly from the normal distribution. The values of Kolmogorov-Smirnov test indicated on this $($ sig< $<.01)$.

Table 2 The values of the Kolmogorov-Smirnov test for analyzing the normal distribution of respondents response on the loneliness scale

\begin{tabular}{lll}
\hline St & df & sig \\
\hline .093 & 676 & .000 \\
\hline
\end{tabular}

A further analysis revealed that respondents to a greater extent are characterized by a lower level of loneliness.

Table 3 Measures of central tendency and variability of responses of respondents on the loneliness scale

\begin{tabular}{cccccccc}
\hline AM & Md & St. dev & Min & Max & R & Sk & Ku \\
\hline 15.050 & 14.000 & 6.509 & 7.00 & 35.00 & 28.00 & .686 & -.170 \\
\hline
\end{tabular}

The positive sign of the skewness (.686) indicates a grouping of data around lower values, that is, a more frequent manifestation of a lower level of loneliness of the respondents. The aforementioned can be noticed on the graphic representation of the distribution of the loneliness of the respondents (Chart 1).

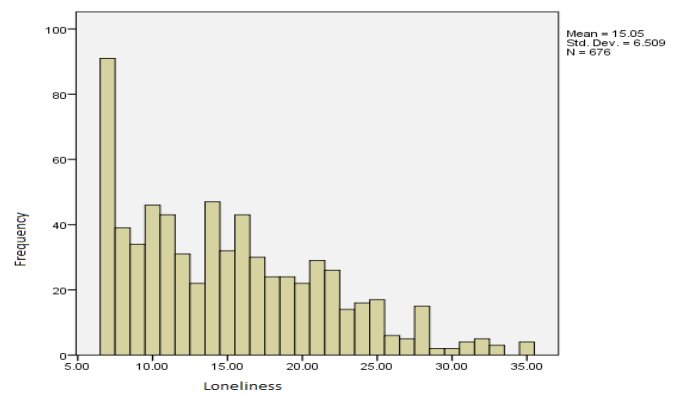

Chart 1. Distribution of loneliness
Using the Mann-Whitney $U$ test, the differences between female and male respondents in loneliness were examined (Table 4).

Table 4 Differences in loneliness of female and male respondents

$\mathrm{U}=3$\begin{tabular}{ccc}
\hline Gender & N & Md \\
\hline Female & 423 & 13.000 \\
Male & 254 & 16.000 \\
\hline Z $=-6.122$ & \multicolumn{2}{c}{ sig $=.000$}
\end{tabular}

Based on the results shown in Table 4, it can be concluded that male respondents are statistically significant $(\mathrm{U}=38672.000, \mathrm{Z}=-6.122, \mathrm{p}=.000)$ characterized to a greater extent by loneliness $(\mathrm{Md}=$ 16.000) than female respondents (13.000).

Furthermore, using the Mann-Whitney U test, the differences between high school and college students in loneliness were examined (Table 5).

Table 5 Differences in the loneliness of high school students and college students

\begin{tabular}{ccc}
\hline Level of Education & N & Md \\
\hline High School Student & 334 & 16.000 \\
College Student & 343 & 13.000 \\
\hline $\mathrm{U}=42292.500 \quad \mathrm{Z}=-5.905$ & sig $=.000$ &
\end{tabular}

The results shown in Table 5 show that there is a statistically significant difference in the loneliness of high school students and college students ( $U$ $=42292.500, \mathrm{Z}=-5.905, \mathrm{p}=.000)$. High school students are more likely to be lonely $(\mathrm{Md}=16,000)$ than college students $(13,000)$.

The use of the Kruskall-Wallis test examined differences in loneliness among the respondents who spent most of their childhood on countryside, in a minor settlement and in a city (Table 6). 
Table 6 Differences in loneliness with regard to where the respondents spent most of their childhood

\begin{tabular}{|c|c|c|}
\hline $\begin{array}{c}\text { The place where most of childhood } \\
\text { was spent }\end{array}$ & $\mathbf{N}$ & Md \\
\hline Countryside & 209 & 15.000 \\
\hline Minor Settlement & 172 & 15.000 \\
\hline City & 285 & 13.000 \\
\hline
\end{tabular}

The obtained results show that there is a statistically significant difference in loneliness with regard to the place where the respondents spent most of their childhood $(\chi 2=9.383, \mathrm{df}=2, \operatorname{sig}=.009)$. Respondents who spent most of their childhood in the city are characterized by a lower level of loneliness $(\mathrm{Md}=$ 13,000) than respondents who spent most of their childhood on the countryside and in a minor settlement $(\mathrm{Md}=15,000)$.

Based on Spearman's correlation coefficient, it has been stated that there is a statistically significant relationship of medium intensity between self-esteem and loneliness $\left(r_{0}=-.401, \operatorname{sig}=.000, N=676\right)$.

Table 7 The corelation of self-esteem and loneliness

\begin{tabular}{ccc}
\hline $\mathbf{r}_{\mathbf{0}}$ & $\mathbf{s i g}$ & $\mathbf{N}$ \\
-.401 & .000 & 676 \\
\hline
\end{tabular}

The negative sign of correlation $\left(r_{0}=-.401\right)$ indicates that a higher expression of one psychological characteristic of the subjects entails a lower expression of another psychological characteristic. Since higher scores on the scales used indicate higher levels of expression and self-esteem and loneliness, a negative sign of correlation indicates that respondents with higher self-esteem are less characterized by loneliness.

\section{DISCUSSION}

Based on the results shown, it can be concluded that the socio-demographic characteristics of the respondents, and the attitude towards oneself, ie self-esteem, are important to explore loneliness. Loneliness refers to the experience of quantity or quality of social relationships. Humans are social beings and as such they strive for social contacts, as well for association with other people, which implies close and intimate relationships with them. The individual lives today in a time of accelerated development and intensive use of technology which, on the one hand, enables a large number of social contacts, and on the other hand disables the quality of those contacts. In addition to the accelerated development of technology, there are changes in the organization of society on a global level, and consequently changes in value systems. The question is whether loneliness is solely determined or there are other factors contributing to loneliness. The obtained results indicate that the problem of loneliness can be explained by a series of psychological aspects that fall within the domain of socialization and personality. An analysis of the distribution of loneliness found that high school students and college students have a lower level of loneliness to a greater extent. Since the survey did not cover younger and older respondents, the results obtained can not be compared with the results of the research, which determined the increase in loneliness in the adolescent period compared to other developmental periods. On the other hand, it is possible to look at the results of the research in the context of social contacts characteristic of the adolescent period. The authors emphasize the various life events that can contribute to loneliness in the period of adolescence, and that this period of development is both physically and psychologically. In this period, there is an abstract thinking that gives the individual new perspectives of thinking and concluding. He can perceive the current state and ideas of the future, but also strive for the more ideal one. It is also the period of identity development. 
Each of these factors can contribute to loneliness, but on the other hand, each one can stimulate a search for new and better-quality social contacts in which the adolescent will try to find answers to various questions.In contact with their peers, they will find similar interests, similar problems, and the expected answers, and will therefore be more satisfied with their own social contacts, and to a lesser extent experience loneliness. On the other hand, it is possible, in this period, that they express their needs and interests more clearly and more actively in front of adults, which enables them to better understand them, and therefore the adolescent perceives interpersonal relationships with them as qualitative, which reduces the possibility of a feeling of loneliness. The results of the study showed that male respondents statistically significantly to a greater extent are characterized by loneliness than female respondents. The obtained results are in accordance with the findings of individual authors (Lacković-Grgin, Penezić, Sorić, 1998; Koc, 2012). The results obtained can be explained by the interpretations of other authors who consider that men are characterized by lower expectations of social relationships and are less invested in them and less realized in them, and to a greater degree feel lonely (Claes, 1992, according to Medved, Keresteš, 2011). It is also possible to seek explanation in the processes of socialization that traditionally direct the children of the male and female gender to invest in various aspects of life. Traditionally, female children are more focused on activities that involve long-term care for others, while male to activities that imply strength and skill. By rewarding certain patterns of behavior, children make them to a greater extent, and develop skills that are important for their realization. Girls are to a greater extent directed towards the realization of close interpersonal relationships, and therefore they invest more in them, and consequently they achieve them in an adequate way, and for this reason they are to a lesser degree characterized by loneliness. Boys rely heavily on skills and strength, and do not underline activities that involve more open communication in terms of recognizing their own weaknesses and fears, and are partly limited in achieving interpersonal relationships that would satisfy them.
Based on the established results of the research, it can be concluded that high school students are characterized by loneliness more than college students. This result is consistent with the results of the research carried out by some other authors (Mahon, 1983; Mijušković, 1986; Nekić, Uzelac, Jurkin, 2016).The results obtained can be explained by the fact that college students have partly already had an idea of what to do in the future, while in front of a large number of high school students there is a choice of a lifelong call.Also, college students are at the end of adolescence, i.e. developmental problems characteristic of adolescence are largely behind them. Also, changes in physical development are in this period of less intensity than in high school students. The results of the survey show that the respondents who spend most of their childhood in the city experience less loneliness than the respondents who spent most of their childhood on a countryside or in a minor settlement. Based on the results of several studies, Jackson, Soderlind, Weiss (2000) cite several aspects of the quality of social relationships that contribute to a lesser sense of loneliness, and its conclusions are based on research that has determined that the quality of social relationships affects to a greater extent loneliness than quantity. Given the established differences between the respondents who have spent childhood in places that are more populated and those who have spent it in a less populated place, it can be assumed that the quality of interpersonal relationships depends on the quantity.Namely, in more populated places, the possibility of choosing social contacts is higher, as well as the possibility of searching for social contacts that will correspond to the individual to a greater extent. By analyzing the obtained results it was found that selfesteem statistically significantly correlates with loneliness. A positive attitude about oneself, evaluating oneself as a capable, significant, successful and valuable one is one of the aspects that enable an individual to enter into social relations more easily and search for the positive aspects of those relationships, and therefore feel a lower level of loneliness. On the other hand, this relationship can be reciprocal. Due to the fact that he does not realize the quantity and quality of social relationships that a person desires, he may consider himself less valuable and less capable than other people. 


\section{CONCLUSIONS}

In the conducted research, it was established that the distribution of loneliness among high school students and college students statistically varies significantly from normal distribution, in the direction of manifesting lower values of loneliness. The differences in loneliness are determined by gender, level of education and the place where most of childhood was spent. Male respondents are characterized by a higher level of loneliness than female respondents, high school students are characterized by higher level of loneliness than college students, and respondents who spend most of their childhood on a countryside and in a minor settlement are more lonely than respondents who spent most of their childhood in the city.Between the self-esteem and loneliness of the respondents, a statistically significant connection of the negative sign was established. In further research, for the purpose of improving knowledge about the problem, it would be desirable to include some other factors that could explain the obtained results (eg, the relationship of parents to male and female respondents, emotional closeness with parents, relationships with peers, etc.).

\section{DECLARATION OF CONFLICTING INTERESTS}

The authors declared no potential conflicts of interest with respect to the research, authorship, and/or publication of this article.

\section{REFERENCES}

Akin, A., (2010). Self-compassion and loneliness. International online journal of educational Sciences, 2(3), 702 718. Retrieved from https://www.researchgate.net/ publication/49591624_Self-compassion_and_Loneliness

Baran, M., Baran, M., \& Maskan, A. (2015). A study on adolescent students' levels of hopelessness, loneliness and self-esteem: A sample from Turkey. Mediterranian journal of social sciences, 6(2), 341-353.

Berk, L. E. (2008). Development through the Lifespan. Jastrebarsko: Naklada Slap.
Byrne, D. G., Davenport, S. C., \& Mazanov, J. (2007). Profiles of adolescent stress: The development of the adolescent stress questionnaire (ASQ). Journal of adolescence, 30, 393-416.

Brage, D., Meredith, W., \& Woodward, J. (1993). Correlates of loneliness among midwestern adolescents. Adolescence, 28 (111), 685-693.

Cash, T. F. (1995). Developmental teasing about physical appearance: Retrospective description and relationships with body image. Social behavior and personality, 23(2), 123-129.

Chipuer,H.,M., \& Pretty,G.,H.(2000). Facets of adolescents' loneliness: A study of rural and urban Australian youth. Australian psychologist,35,233-237.

De Jong Gierveld, J., van Tilburg, T., \& Dykstra, P., A. (2006). Loneliness and Social Isolation. In Vangelisti, A., Perlman, D. (Ed.), Camridge handbook of personal relationships (485-500). Cambridge: Cambridge University Press.

De Jong Gierveld, J. (1998). A review of loneliness: concept and definitions determinants and consequences. Reviws in clinical gerontology, 8, $73-80$.

Hawkley, L., C., \& Cacioppo, J., T. (2010). Loneliness matters: a theoretical and empirical review of consequences and mechanisms. Annals of behavioral medicins, 40(2), 218 227.

Heatherton, T., F., \& Voks, K., D. (2000). Interpersonal evaluations following threats to self: Role of self-esteem. Journal of personality and social psychology, 78(4), 725736.

Hombrados - Mendieta, I., García - Martín, M., A., \& Gómez - Jacinto, L. (2012). The relationship between social support, loneliness, and subjective well-being in a Spanish sample from a multidimensional perspective. Social indicators research. Retrieved from http://webdeptos. uma.es/psicologiasocial/docs_magarcia/37_2012_social_ Indicators_research_soc_support_loneliness_and_subj_ well_Being.pdf

Jackson, T., Soderlind, A., Weis, K., E. (2000). Personality traits and quality of relationships as predictors of future loneliness among American college students. Social behavior and personality, 28(5), 463-470.

Javeed, Q. S. (2011). A study of loneliness and self-concept of male and female adolescences. Indian streams research journal, 2, 1-4.

Koc, Z. (2012). Determination of older people's level of loneliness. Journal of clinical nursing, 21, 3037-3046.

Lacković, K., Penezić, Z., \& Sorić, I. (1998). Usamljenost i samoćas tudenata: uloga afilijativn emotivacije i nekih osobnih značajki. Društvena istraživanja, 7(4-5), 543-558. 
Lacković-Grgin, K., Penezić, Z. \& Nekić, M. (2002). A short version of the UCLA Loneliness Scale. In: K. LackovićGrgin, A. Proroković, V. Ćubela, Z. Penezić (Ed.), Collection of Psychological Scales and Questionnaires (77-78). Zadar: Faculty of Philosophy. PREVEST

Lasgaard, M., \& Elklit, A. (2009). Prototypic features of loneliness in a stratified sample of adolescents. Interpersona, 3(1), 85-110.

Mahon, N. E. (1983). Developmental changes and loneliness during adolescence. Topicsin clinical nursing, 5(1), 66-76.

Medved, A. \& Keresteš, G. (2009). Loneliness in early adolescence: gender and age differences and association with social relationships. Social research, 20, 457-478.

Mijušković, B. (1986). Loneliness, anxiety, hostility, and communication. Child study journal, 16(3), 227-240.

Milošević, N., \& Ševkušić, S. (2005). Student self-esteem and school achievement. Proceedings of the Institute for Educational Research, 1, 70-87.

Moon, S. S., \& Rao, U. (2010). Youth-family, youth-school relationship, and depression. Child and adolescent social work journal, 27, 115-131.

Nekić, M., Uzelac, E., \& Jurkin, M. (2016). The role of selfesteem and peer pressure in explaining adolescent loneliness. Acta Iadertina, 13/1, 41-63.

Neto, F. (2014). Socio-demographic predictors of loneliness acros the adult life span in Portugal. Interpersona, 8(2), 222-230.

Rosenberg, M. (1965). Society and the adolescent self-image. Princeton, NJ: Princeton University Press.

Rubin, K., H., \& Mills, R., S., L. (1991). Conceptualizing developmental pathways to internalizing disorders in childhood. Canadian journal of behavioral science, 23(3), 300-317.
Simons, R., G. (1987). Self-Esteem in Adolescence. In: Honess, T., Vardley, K., M. (Ed.), Perspectives across the Lifespan (str. 172-192). London: Kegan Paul Ltd.

Stikley, A. et al. (2016). Loneliness and its association with psychological and somatic health problems among Czech, Russian and U.S. adolescents. BMC Psychiatry. Retrieved from sahttps://bmcpsychiatry.biomedcentral.com/ articles/10.1186/s12888-016-0829-2

Thorsteinsson, E. B., Ryan, S. M., \& Sveinbjornsdottir, S. (2013). The mediating effects of social support and coping on the stress-depression relationship in rural and urban adolescents. Open journal of depression, 2, 1-6.

Tucak Junaković, I., Nekić, M., \& Burić, I. (2013) Loneliness and Preferred Solitude as Predictors of Self-rated Health of Adults, Medica Jadertina, (43) 1-2, 1121.

Vanhalst, J., Luyckx, K., Scholte, R., H., Engels, R., C., \& Goosens, L. (2013). Low self-esteem as a risk factor for loneliness in adolescence: perceived - but not actual social acceptance as an underlying mechanism. Journal of abnormal child psychology, 41(7), 1067-1081.

Victor, C. R., \& Yang, K. (2012). The prevalence of loneliness among adults: A case study of United Kingdom. The journal of psychology, 146, 85-104.

Woodward, J., C., \& Kalyan-Mashis, V. (1990). Loneloness, coping strategies and cognitive styles of the gifted rural adolescent. Adolescence, 25(100), 977-988. 